ISSN 1676-3742

\title{
A doutrina da encarnação na teologia cristã das religiões e o diálogo inter-religioso
}

\author{
Elismar Alves dos Santos, CSsR.
}

\section{Resumo}

O artigo está dividido em três partes. A primeira apresenta uma retrospectiva acerca da proposta de alguns teólogos sobre o tema em discussão: a doutrina da Encarnação na Teologia Cristã das Religiões. Entre eles Jonh Hick, Aloysisus Pieris, Paul Knitter, Jacques Dupuis e Claude Geffré, com a tentativa de sublinhar os principais pontos subjacentes à proposta cristológica em vista da construção de uma Teologia Cristã das Religiões. A segunda, por sua vez, apresenta algumas considerações da proposta do Magistério Eclesiástico relacionado ao diálogo inter-religioso. E, por último, a terceira parte descreve cinco bases teológicas para melhor situar a Cristologia, com a finalidade de propor elementos a serem considerados em uma Teologia Cristã das Religiões na atualidade.

Palavras-chaves: Encarnação, Cristologia, Teologia Cristã das Religiões, Diálogo inter-religioso. 


\begin{abstract}
This article is divided into three parts. The first presents a retrospective on the proposal of certain theologians on the subject: the Incarnation in the Christian Theology of Religions. Among them are Jonh Hick, Aloysius Pieris, Paul Knitter, Jacques Dupuis and Claude Geffre, with the attempt to highlight the main points underlying to the christological proposal in view of the construction of a Christian Theology of Religions. The second part presents some considerations upon the Ecclesiastical Magisterium proposal related to inter-religious dialog. And the third part describes five theological bases to better situate Christology, with the goal of proposing elements to be considered in a Christian Theology of Religions in the present.
\end{abstract}

Key-words: Incarnation, Christology, Christian Theology of Religion, Interreligious dialog.

\title{
Introdução
}

No estudo da Teologia Cristã das Religiões, emerge o emblemático dessa área: a Cristologia. Como dado histórico, sabe-se que, no momento do nascimento do Cristianismo, já havia uma pluralidade de religiões ${ }^{1}$. Como por exemplo, o Judaísmo; as religiões da Assíria antiga; a religião dos Romanos (culto pagão) e a religião dos Gregos. "O cristianismo é, com certeza, religião que repousa sobre acontecimentos históricos bem determinados" ${ }^{2}$. Desde o início, o Cristianismo precisou afirmar sua identidade, deixando de ser uma "seita" do Judaísmo para torna-se uma religião. Entretanto, os estudiosos afirmam que o Cristianismo contemporâneo necessita fazer uma revisão, pois corre o risco de fechar-se em si, devido ao Pluralismo Religioso na atual conjuntura mundial. Mas, em meio a tudo isso, deve redescobrir sua identidade tendo, subjacente o Evento Pascal de Cristo na experiência da Encarnação e da Ressurreição.

\footnotetext{
${ }^{1}$ Cf. DUPUIS, Jacques. El Diálogo Interreligioso, desafio y oportunidad. Selecciones de Teología, n. 538, p. 125, 2004.

${ }^{2}$ RAHNER, Karl. Curso Fundamental da Fé: Introdução ao conceito de cristianismo. São Paulo: Paulus, 2008, p.9.
} 


\section{Teologia Cristã das Religiões}

O direito à liberdade é um fato no mundo contemporâneo, ao menos nos países considerados democráticos. Essa liberdade atinge também a Teologia Cristã das Religiões, pois parte-se de uma autocompreensão da teologia na perspectiva do diálogo com as outras religiões. Em outras palavras: "a teologia das religiões deve mostrar a maneira em que os 'outros' participam do reino de Deus, ao abrir-se a ação do Espírito mediante a prática sincera de sua tradição religiosa"’. Daí surgem ao menos dois questionamentos: as religiões são caminhos de salvação? As religiões sem Cristo promovem a salvação? Entre os estudiosos da Teologia das Religiões, John Hick ${ }^{4}$ posiciona-se quanto à questão da Encarnação, o que ele chama de "A Metáfora do Deus Encarnado", para dizer que a doutrina dos cristãos levou-os a ter uma posição de intolerância (superioridade) em relação às outras religiões.

Segundo John Hick, o Cristianismo tornou-se a Religião. Portanto, necessita passar de um modelo exclusivista, para um modelo inclusivista em vista do pluralismo religioso. A proposta teológica desse autor explicita que Jesus não é a única mediação de salvação. Quem é Jesus para ele? Um simples "Guru", um mestre de ética que ensina algumas maneiras práticas de se viver a vida, um mestre adorado por seus discípulos? Percebe-se, assim, que a problemática abordada pela Teologia Cristã das Religiões corresponde, portanto, ao dado bíblico da Encarnação.

Já Aloysius Pieris ${ }^{5}$ propõe não falar mais de Cristologia Descedente, mas de uma Cristologia "Adiante", de um Deus em movimento. Por outro lado, encontra-se em Paul Knitter ${ }^{6}$ uma crítica pertinente à posição de Karl Rahner sobre a presença de Cristo nas outras religiões. Primeiramente, vejamos o que escreve Karl Rahner: "Existe certamente algo como um cristianismo anônimo no qual acontecem graças, remissão dos pecados, justificação e salvação sem que o interessado, em sua consciência objetivada, refira-se explicitamente ao evento histórico de Jesus de Nazaré"’

\footnotetext{
${ }^{3}$ DUPUIS, Jacques. El Diálogo Interreligioso, desafio y oportunidad, p.127.

${ }^{4}$ Cf. HICK, John. A Metáfora do Deus Encarnado. Petrópolis: Vozes, 2000, p.136-151.

${ }^{5}$ Cf. PIERIS, Aloysisus. Cristo más allá del dogma. Hacer cristología en el contexto de las religiones de los pobres (II). Revista Latinoamericana de Teologia, n.53, p. 107, 2001.

${ }^{6}$ Cf. KNITTER, Paul. La Teologia de las Religiones en el pensamiento catolico. Concilium, n. 203, p. 123-134, 1986. Na tradução em espanhol, o que foi dito logo acima se encontra na página 2.

${ }^{7}$ RAHNER, Karl. Curso Fundamental da Fé, p.522.
} 
A crítica que Paul Knitter faz à afirmação de Karl Rahner consiste no fato de conceber o Cristianismo como religião superior às demais. A propósito desse tema, como escreve Gibellini:

\begin{abstract}
De acordo com a tese do cristianismo anônimo, todo homem, enquanto homem, não abstratamente considerado em sua natureza humana, mas concretamente considerado na presente ordem histórica de economia salvífica, pode ser cristão anônimo, embora nem sempre seja cristão explícito. Deus quer a salvação de todos e, graças a essa vontade salvífica universal, a todos oferece a possibilidade da salvação (existencial sobrenatural $)^{8}$.
\end{abstract}

Segundo Paul Knitter, o Cristianismo, nessa acepção, encontra-se "acima" das outras religiões. Ele lembra, positivamente, que Cristo é constitutivo para a salvação dos cristãos, é normativo para os que professam a fé N'ele, mas não é normativo para as outras religiões. Em sua avaliação, a doutrina da Encarnação é culpada por todas as catástrofes em matéria de diálogo inter-religioso, como superioridade transformada em absolutismo.

Além desses teólogos, há também o esforço de Jacques Dupuis ${ }^{9}$ na área da Cristologia aplicada ao estudo reflexivo do Pluralismo Religioso. Ele

\footnotetext{
${ }^{8}$ GIBELLINI, Rosino. A Teologia do Século XX. São Paulo: Loyola, 1998, p, 231-232. "Esta tese rahneriana do cristianismo anônimo despertou muitas críticas: a) antes de mais nada, sobre a própria terminologia: o cristianismo ou é explícito, ou não é cristianismo. Mas Rahner pode fazer valer a instância a respeito do como se possa falar, teologicamente, de real possibilidade de salvação, cristãmente caracterizada, também para os não-cristãos; b) a tese, além disso, comportaria uma anexação indevida de outras crenças e ideologias. Mas, segundo Rahner, a tese do cristianismo anônimo não deve ser usada em sentido apologético para atribuir a outros um rótulo que eles ignoram ou não desejam; mas somente como tese que torna compreensível, em nível intra-teológico, a possibilidade da salvação também para os não cristãos. A tese do cristianismo anônimo é apenas um instrumento interpretativo para quem professa explicitamente o cristianismo, para que compreenda que todo homem, mesmo se não batizado, mesmo se ateu, o qual entretanto aceite e viva o sentido positivo da existência, vive também ele, se bem que de forma anônima, o cristianismo como economia de salvação; c) finalmente, a tese - e é a objeção mais relevante - poderia significar uma relativização do cristianismo histórico e consequentemente da missão cristã. Mas, na teoria rahneriana, o cristianismo explícito não possui apenas um 'acréscimo de conhecimento', mas também um 'acréscimo de ser', que impede qualquer nivelamento do cristianismo explícito com o cristianismo implícito; pelo contrário, necessariamente remete aquele que é chamado de cristianismo anônimo para o cristianismo histórico e explícito, e apela para a missão". (p.232-233).

${ }^{9}$ Cf. DUPUIS, Jacques. El Pluralismo Religioso en el plan divino de salvación. Revue Théologique de Louvain, Bélgica, n. 29, p. 884-505, 1998 aqui p. 3-5.
} 
propõe uma teologia do Pluralismo elaborado a partir da Cristologia Trinitária que deverá manter unidos o caráter central do acontecimento histórico de Jesus Cristo e a ação universal. Porém, no que corresponde à fé cristã, deve-se perguntar: existe uma Cristologia que não seja trinitária? Ou ainda: existe uma Pneumatologia não trinitária?

Por último, Claude Geffré10, por outro lado, apresenta "Cristo como Universal Concreto" para estabelecer uma discussão teológica em vista ao Pluralismo Religioso na atualidade. A novidade do Cristianismo enquanto religião consiste na matização do Evento Jesus Cristo que propõe uma nova maneira de relacionar-se com Deus e com as outras pessoas. Sobre a Encarnação, Claude Geffré explica que há uma concepção de um Deus que se fez humano, isto é, o princípio absoluto convida o Cristianismo a não ter a pretensão de ser a religião absoluta.

Nessa perspectiva, segundo Claude Geffré, o Cristianismo é convidado a dar testemunho de uma religião dialogal. Na sua análise acerca da Cristologia Geffré lembra que Jesus não fundou uma religião enquanto ritos e preceitos. O Cristianismo precisa ser tomado como a religião do amor e da alteridade, pois o Deus cristão "abre mão" da condição divina (Kenosis) e torna-se humano. Com isso, ao se tornar humano em Jesus de Nazaré, o Absoluto de Deus (ou o Verbo de Deus Encarnado) entra e participa concretamente da história da humanidade.

Entretanto, Claude Geffré delineia incontestavelmente um paradoxo: "ao confessar Jesus como o Filho de Deus, a Igreja reivindica para o Cristianismo uma unicidade por excelência com respeito a todas as demais religiões"11. Nessa mesma ótica, enfatiza que a tarefa da Teologia Cristã das Religiões consiste, às vezes, em afirmar o caráter único do Cristianismo, que remete ao acontecimento Jesus Cristo, e não absolutilizá-lo como uma religião dominadora e excludente de todas as demais. Para ele, a unicidade do Cristianismo deve ser tomada não como exclusiva ou inclusiva, mas assumido como unicidade relativa.

Claude Geffré enfatiza que a Teologia Cristã, na atual conjuntura, precisa manifestar-se melhor que a verdade do Cristianismo nem exclui nem inclui as verdades das outras tradições religiosas. O diálogo inter-religioso não deve

${ }^{10}$ Cf. GEFFRÉ, Claude. La Verdad del Cristianismo en la era del Pluralismo Religioso. Angelicum. Roma, n. 74, p. 171-191, 1997 aqui corresponde às páginas 138-140. Na tradução para o espanhol, as páginas são de 135-144. Aqui a citação corresponde às páginas 138-140.

${ }^{11}$ GEFFRÉ, Claude. La Verdade del Cristianismo en la era del Pluralismo Religioso, p.139. 
entrar na questão de discussão sobre o que é a verdade. Mas, segundo Cornille Catherine, "o objetivo último do diálogo inter-religioso é a busca da verdade, ou crescimento na verdade"12. Sabe-se que "o diálogo inter-religioso envolve um intercâmbio aberto e construtivo entre indivíduos pertencentes a diferentes religiões"13. O diálogo inter-religioso precisa ser pautado no respeito e no amor, e não em verdades, pois cada experiência religiosa já possui suas próprias verdades.

Ou ainda, o diálogo inter-religioso "baseia-se também na premissa ou crença de que pode haver mais verdade entre duas ou mais tradições do que em qualquer religião isoladamente"14. Quanto ao diálogo inter-religioso, Claude Geffré ${ }^{15}$ acredita no diálogo pautado na igualdade entre os interlocutores. Entretanto, em sua observação, o Cristianismo apresenta dificuldades devido à unicidade da mediação de Cristo no horizonte do Pluralismo Religioso. Daí pode-se afirmar que a maior dificuldade acerca da Teologia Cristã das Religiões encontra-se na Cristologia.

O diálogo com as outras religiões não é um fato somente sociológico. É, também e profundamente, teológico. O Evangelho de Marcos, por exemplo, sugere a olhar para Jesus e observar que Ele chama ao diálogo inter-religioso: “a minha casa será chamada de 'Casa de Oração' para todos os povos” $(11,17)$. Sabe-se onde Deus está, mas não se sabe onde Ele não está. A pessoa humana, na ótica cristã, é tomada sempre como realidade relacional. O diálogo inter-religioso fala dessa questão relacional, porque a pessoa é vista na condição de "seres com outros". Hoje, portanto, ser religioso significa ser "inter-religioso". Nenhuma religião existe de modo isolado das outras religiões. De modo que nenhuma religião é uma ilha. A Igreja Católica, por sua vez, se preocupa com o dado bíblico da Encarnação como fator motivacional para o diálogo inter-religioso.

\footnotetext{
${ }^{12}$ CORNILLE, Catherine. O papel do testemunho no diálogo inter-religioso. Concilium, Petrópolis, n.339, p. 63, 2011.

${ }^{13}$ CORNILLE, Catherine. O papel do testemunho no diálogo inter-religioso, p.63. "Todo diálogo pressupõe certo nível de intercâmbio puramente informacional e a acumulação de conhecimento sobre a outra religião. Mas, enquanto conhecimento e compreensão são o objetivo mais alto do estudo da religião, o diálogo ocupa-se com a possibilidade de fecundação mútua, de inspiração recíproca, e mesmo de transformação" (p.63).

${ }^{14}$ CORNILLE, Catherine. O papel do testemunho no diálogo inter-religioso, p.64.

${ }^{15}$ GEFFRÉ, Claude. Para un Cristianismo Mundial. Selecciones de Teología, Véase, n. 146, p. 135-144, 1998. Aqui, na tradução ao espanhol, páginas 4-5.
} 


\section{Diálogo inter-religioso e Magistério Eclesiástico}

O diálogo inter-religioso faz parte da missão evangelizadora da Igreja Católica como atesta, por exemplo, o Papa Paulo VI, em 1975, na Encíclica Evangelii Nuntiandi ${ }^{16}$. Sobre esse tema, a Declaração Nostra Aetate apresenta alguns ensinamentos pertinentes: "todos os povos, com efeito, constituem uma só comunidade. Têm uma origem comum, uma vez que Deus fez todo o gênero humano habitar a face da terra"17. A propósito da relação entre cristãos e muçulmanos, a Declaração expressa os pontos semelhantes entre Cristianismo e Islamismo e, mais especificamente, ainda, as semelhanças entre as duas confissões religiosas.

A Igreja igualmente os vê com carinho, porque adoram a um único Deus, vivo e subsistente, misericordioso e onipotente, Criador do céu e da terra, que falou aos homens. A seus ocultos decretos esforçam-se por submeter-se toda a alma, como a Deus se submeteu Abraão, a quem a crença mulçumana se refere com agrado. Não reconhecem Jesus como Deus; veneram-n'O, no entanto, como profeta. Honram Maria, Sua mãe virginal, e até a invocam às vezes com devoção. Aguardam, além disso, o dia do juízo, quando Deus há de retribuir a todos os homens ressuscitados. Como conseqüência, valorizam a vida moral e honram a Deus, sobretudo pela oração, esmola e jejum ${ }^{18}$.

Encontra-se também no Magistério Eclesiástico de João Paulo II, sobretudo na Redemptoris Missio uma chave de leitura voltada à compreensão do diálogo inter-religioso com as outras religiões. Segundo o Papa, o "diálogo inter-religioso faz parte da missão evangelizadora da Igreja"19. E ainda, na Ecclesia in Asia, ele explica claramente que o diálogo inter-religioso "é uma parte da missão evangelizadora da Igreja, uma expressão da missão $a t$ gentes" $^{\prime 20}$. E, na Encíclica Sollicitudo Rei Socialis:

${ }^{16}$ Cf. PAULO VI, Encíclica Evangelii Nuntiandi, n.49 e 75. In: DENZINGER, H. HÜNERMANN, P. Compêndio dos símbolos, definições e declarações de fé e moral. São Paulo: Paulinas \& Loyola, 2007, p. 1079-1082.

${ }^{17}$ CONCÍlIO DO VATICANO II, Declaração Nostra Aetate. In: Compêndio do Vaticano II, Petrópolis: Vozes, 1995, n. 1.

${ }^{18}$ CONCÍlIO DO VATICANO II, Declaração Nostra Aetate, n.3.

${ }^{19}$ JOÃO PAULO II, Encíclicas de João Paulo II, Redemptoris Missio. In: Documentos da Igreja, São Paulo: Paulus, 2006, n.55.

${ }^{20}$ JOÃO PAULO II, Eclesia in Asia,. São Paulo: Paulus, 2005, n. 31. 
O encontro de 27 de outubro do ano passado em Assis, a cidade de São Francisco, para rezarmos e nos empenharmos pela paz - cada um na fidelidade à própria profissão religiosa - revelou a todos até que ponto a paz e, como sua necessária condição, o desenvolvimento do 'homem todo e de todos os homens', são uma questão também religiosa, e até que ponto realização plena de um e do outro depende da fidelidade à nossa vocação de homens e mulheres que acreditam ${ }^{21}$.

Recentemente, o Papa Bento XVI, na sua Mensagem para a Celebração da Jornada Mundial da Paz de 2011, recordou da necessidade da tolerância religiosa, em vista dos constantes conflitos envolvendo a Igreja Siro-Católica, Nossa Senhora do Perpétuo Socorro, em Bagdá, onde, no dia 31 de outubro, foram assassinados dois sacerdotes e mais de cinquenta fiéis por grupos radicais islâmicos. "Em tal contexto, sinto particularmente viva a oportunidade de convidar a todos vocês a uma reflexão sobre a liberdade religiosa, pela busca da paz"22. Em outro momento, Bento XVI ressalta que "a liberdade religiosa, encontra expressão na especificidade da pessoa humana, que pode ordenar a própria vida pessoal e social a Deus" ${ }^{\prime 2}$. Mais especificamente, ainda, recorda que "todos são livres para professar a própria religião ou a própria fé, e de viver o próprio amor a Deus com todo o coração, com toda a alma e com toda a mente (cf. Mt 22,37)"24. Na Encíclica Caritas in Veritate, Bento XVI ressalta a importância do "direito à liberdade religiosa" 25 como recurso necessário ao desenvolvimento do ser humano.

A propósito da liberdade religiosa, a Declaração Dignitatis Humanae lembra que "os homens todos devem ser imunes da coação tanto por parte de pessoas particulares quanto de grupos sociais e de qualquer poder humano, de tal sorte que em assuntos religiosos ninguém seja obrigado a agir contra a própria consciência, nem impeça de agir de acordo com ela, em particular dos devidos limites”26.

${ }^{21}$ JOÃO PAULO II, Encíclicas de João Paulo II, Sollicitudo Rei Socialis. In: Documentos da Igreja, São Paulo: Paulus, 2006, n. 47.

22 BENEDETTO XVI. Messaggio per la Celebrazione della Giornata Mondiale della Pace 2011. Vaticano: Libreria Editrice Vaticana, 2011, p.4.

${ }^{23}$ BENEDETTO XVI. Messaggio per la Celebrazione della Giornata Mondiale della Pace 2011, p.5.

${ }^{24}$ BENEDETTO XVI. Messaggio per la Celebrazione della Giornata Mondiale della Pace 2011, p.6.

${ }^{25}$ BENTO XVI, Carta Encíclica Caritas in Veritate. São Paulo: Paulinas, 2009, n. 29. "Na realidade, com frequência hoje se faz apelo ao santo nome de Deus para matar [...]. Isto se aplica de modo especial ao terrorismo de índole fundamentalista, que gera sofrimento, devastação e morte, bloqueia o diálogo entre as nações e desvia grandes recursos do seu uso pacífico e civil". ${ }^{26}$ CONCÍLIO DO VATICANO II, Declaração Dignitatis Humanae . In: Compêndio do Vaticano 
Significa, segundo a mencionada Declaração, que "o direito à liberdade religiosa se funda realmente na própria dignidade da pessoa humana". E, para concluir essa parte, o teólogo Edward Schillebeeckx lembra oportunamente sobre o papel da Igreja diante do diálogo inter-religioso: "A Igreja é o Sacramento do diálogo"27.

\section{As cinco bases para a construção da Teologia Cristã das Religiões}

Com as reflexões apresentadas pelos teólogos Jonh Hich, Aloysius Pieris, Paul Knitter, Jacques Dupuis e Claude Geffré e as considerações do Magistério Eclesiástico, pode-se afirmar que o fator motivacional e fundamental para o diálogo inter-religioso é sempre Deus. Pode-se pensar, por exemplo, em uma posição dialógica tendo os olhos fixos no dado bíblico da Encarnação. A Cristologia não pode tornar-se um empecilho para o diálogo inter-religioso. Quando a teologia da Encarnação torna-se bem compreendida, tal ato possibilita ter uma atitude de humildade, o que se chama de Kénosis Cristã.

A partir daí, pode-se pensar em cinco bases teológicas para orientar uma tentativa de construção de uma Cristologia em vista da Teologia Cristã das Religiões, ressaltando-se, é claro, o aspecto dialógico. Assim, tendo subjacente esse caráter dialógico, apresentar-se-ão, à luz da teologia do teólogo José Kuttianimattathil ${ }^{28}$, as cinco bases, porém dá-se relevo à base Cristológica. As bases são: Trinitária, Cristológica, Pneumatológica, Basiléica (em vista ao Reino de Deus) e Eclesial.

Primeiramente, a Teologia Cristã das Religiões necessita de uma Base Trinitária: a Trindade é uma comunidade de pessoas em comunhão. Significa que o cristão é criado à imagem e semelhança de Deus, e chamado a participar da vida divina. A vida sobre a terra deve ser uma reflexão sobre a experiência trinitária: uma vida em comunhão com os outros e não isoladamente. Segundo Peter C. Phan ${ }^{29}$, a própria Encarnação de Jesus remete-se, como Igreja, a não se esquecer da dimensão trinitária da fé que cada crente professa.

Quanto à Base Cristológica, essa não trata somente do Mistério Crístico, universalmente presente e ativo, mas também, de fato, do diálogo entre Deus

II, Petrópolis: Vozes, 1995, n. 2.

${ }^{27}$ SCHILLEBEECKX, Edward. The Church as a Sacrament of Dialogue, in God the Future of Man. New York: Schee \& Ward, 1968, p. 117.

${ }^{28}$ KUTTIANIMATTATHIL, José. Pratice end Theology of Intrreligious Dialogue. Bangalore: Kristu Jyoti Publications, 1998, p. 585-587.

${ }^{29}$ Cf. PHAN, C. Peter. Being Religious Interreligiously: Asian Perspectives of Interfaith Dialogue. New York: Orbis Books, 2004, p.xix. 
e os seres humanos, que se tornou visível e tangível através da Encarnação do Verbo. Em Jesus, o diálogo divino-humano é completamente revelado. É "diálogo na carne" ${ }^{30}$, como lembra a Dei Verbum. Como participante da missão de Jesus, o cristão é chamado a qualificar melhor o diálogo divino-humano entre todos os povos.

Em terceiro, precisa-se também da Base Pneumatológica, da presença onipotente do Espírito de Deus que faz das outras religiões "casa do Espírito de Deus". A presença e atividade de Jesus Cristo e o Espírito de Deus resulta, sobretudo, no fato de que a vida pode ser mais bem participada em relação com os outros, como resposta ao não isolamento. Portanto, o diálogo desponta-se como uma maneira de encontrar a verdade.

Uma quarta perspectiva corresponde à Base Basileica: o Reino de Deus como temática da Cristologia. O ser humano é chamado a trabalhar em colaboração. Pois todos são filhos de Deus. E, por fim, há a Base Eclesial. A Igreja Católica, como vem demonstrando ao longo dos séculos, procura sempre assumir uma postura de "peregrina" nesse mundo e a sua natureza como sinal e instrumento do Reino de Deus, e mostra, assim, a importância da dimensão eclesial. Como sinal e instrumento do Reino, têm o compromisso de testemunhar e de construir o Reino. Nessa última base, o Reino de Deus precisa ser tomado como sinal de cooperação com todos que são membros desse mesmo Reino. Assim, como Igreja "peregrina", é natural juntar-se aos outros peregrinos, para construir o modo de entender e de empenhar-se no plano de Deus e caminhar juntos em direção a Deus que é Pai de todos.

Dessa maneira, quando se fala de Pluralismo Religioso, para o cristão, fala-se também de Cristologia, a qual deve tornar-se o centro das discussões sobre o diálogo. Em outras palavras, "o diálogo inter-religioso estimula a descobrir o significado da presença de Cristo e do Espírito e de aprofundar a própria identidade" ${ }^{\prime 31}$. O diálogo pressupõe a integridade da fé pessoal, igualmente exige a abertura à fé do outro e constata que aquele é diferente, pois "o diálogo inter-religioso exige dos interlocutores um esforço positivo para entrar na experiência religiosa do outro" 32 .

\footnotetext{
${ }^{30}$ CONCÍlIO DO VATICANO II, Constituição Dogmática Dei Verbum. In: Compêndio do Vaticano II, Petrópolis: Vozes, 1995, n. 28.

${ }^{31}$ DHAVAMONY, Mariasusai. Pluralismo Religioso e Missione della Chiesa. Libreria Editrice Vaticana, 2001, p. 192.

${ }^{32}$ DUPUIS, Jacques. El Diálogo interreligioso, desafio y oportunidad, p.130.
} 
Em outras palavras, "o diálogo pressupõe certo grau de humildade no testemunhar" ${ }^{\prime 3}$. O teólogo jesuíta Hans Urs von Balthasar oportunamente recorda que uma das principais vocações do Cristianismo consiste em unificar "os fragmentos, como libertador dos laços que nos oprimem e enredam e, finalmente, como aquele que nos permite retornar dos caminhos errados" 34 .

\section{Conclusão}

Com o percurso realizado, ficou matizado, especialmente com as perspectivas teológicas apresentadas pelos teólogos da Teologia Cristã das Religiões, que a problemática passa pelo dado bíblico da Encarnação. Percebe-se que existem diversas maneiras de se compreender o significado da Encarnação do Verbo. Não obstante as divergências teológicas sobre a Encarnação, não se deve perder de vista que o caminho ao diálogo inter-religioso não pode ser outro senão uma base sólida à luz da Cristologia. Essa, por sua vez, bem compreendida, impede de se cometerem equívocos teológicos, pois o maior desafio encontra-se nesse ponto.

A Igreja, como Sacramento do diálogo, reconhece seu papel como defensora e facilitadora na promoção do diálogo inter-religioso. Para ela, Deus oferece a todos os seres humanos a possibilidade de habitar em Deus. Daí emerge a consciência da não discriminação das demais religiões. Ora, o diálogo inter-religioso faz parte do caráter missionário e de evangelização da Igreja Católica.

Por último, analisaram-se as cinco bases teológicas apresentadas (Trinitária, Cristológica, Pneumatológica, Basileica e Eclesial). Indiscutivelmente, elas dependem de uma correta posição Cristológica. Fala-se muito, nos dias de hoje, em diálogo inter-religioso. No entanto, um cristão, para um diálogo sólido e teologicamente articulado, não deve se esquecer de que precisa considerar o dado bíblico da Encarnação do Verbo de Deus, pois é central, e deste dado emerge o aspecto dialógico da fé cristã.

\footnotetext{
${ }^{33}$ CORNILLE, Catherine. O papel do testemunho no diálogo inter-religioso, p.64.

${ }^{34}$ BALTHASAR, Hans Urs von. Sólo el Amor es Digno de Fe. Salamanca: Ediciones Sígueme, 2006, p.22.
} 


\section{Referências Bibliográficas}

BALTHASAR, Hans Urs von. Sólo el Amor es Digno de Fe. Salamanca: Ediciones Sígueme, 2006.

BENEDETTO XVI. Messaggio per la Celebrazione della Giornata Mondiale della Pace 2011. Vaticano: Libreria Editrice Vaticana, 2011.

BENTO XVI. Carta Encíclica Caritas in Veritate. São Paulo: Paulinas, 2009, n.193.

CORNILLE, Catherine. O papel do testemunho no diálogo inter-religioso. Concilium. Petrópolis: Vozes, n. 339, p.63-72, 2011.

CONCÍlio DO VATICANO II, Constituição Dogmática Dei Verbum. In: Compêndio do Vaticano II, Petrópolis: Vozes, 1995.

CONCÍLIO DO VATICANO II, Declaracão Nostra Aetate. In: Compêndio do Vaticano II, Petrópolis: Vozes, 1995.

CONCÍlIO DO VATICANO II, Declaração Dignitatis Humanae. In: Compêndio do Vaticano II, Petropólis: Vozes, 1995.

DHAVAMONY, Mariasusai. Pluralismo Religioso e Missione della Chiesa. Libreria Edetrice Vaticana, 2001.

DUPUIS, Jacques. El Pluralismo Religioso en el plan dinino de salvación. Revue Theologique de Laouvain, Bélgica, n.29, 1998.

DUPUIS, Jacques. El Diálogo Interreligioso, desafío y oportunidad. Selecciones de Teología, n.538, p.125-131, 2004.

GEFFRÉ, Claude. La Verdad del Cristianismo en la era del Pluralismo Religioso. Angelicum. Roma, n.74, 1997.

GEFFRÉ, Claude. Para un Cristianismo Mundial. Selecciones de Teología, Véase, n.146, 1998.

GIBELLINI, Rosino. A Teologia do Século XX. São Paulo: Loyola, 1998.

HICK, Jonh. A Metáfora do Deus Encarnado. Petrópolis: Vozes, 2000.

PIERIS, Aloysisus. Cristo más allá del dogma: Hacer cristología en el contexto de las religiones de los pobres (II). Revista Latinoamericana de Teologia, n. 53, 2001. 
JOÃO PAULO II, Encíclicas de João Paulo II, Redemptoris Missio. In: Documentos da Igreja, São Paulo: Paulus, 2006.

JOÃO PAULO II, Encíclicas de João Paulo II, Sollicitudo Rei Socialis. In: Documentos da Igreja, São Paulo: Paulus, 2006.

JOÃO PAULO II. Eclesia in Asia. São Paulo: Paulus, 2005.

KNITTER, Paul. La Teologia de las Religiones en el pensamiento catolico. Concilium, n. 203, 1986.

KUTTIANIMATTATHIL, José. Practice and Theology of Interreligious Dialogue. Bagalore: Kristu Jyoti Publications, 1998.

PAULO VI, Encíclica Evangelli Nuntiandi, n.49 e 75. In: DENZIGUER, H. HÜNERMANN, P. Compêndio dos símbolos, definições e declarações de fé e moral. São Paulo: Paulinas \& Loyola, 2007.

PHAN, Peter C. Being Religious Interreligiously: Asian Perspectives of Interfaith Dialogue. New York: Orbis Books, 2004.

RAHNER, Karl. Curso Fundamental da Fé: Introdução ao conceito de cristianismo. São Paulo: Paulus, 1989.

SCHILLEBEECKX, Edward. The Church as a Sacrament of Dialogue, in God the Future of Man. New York: Shee \& Ward, 1968.

Elismar Alves dos Santos, CSsR

Mestre em Psicologia Clínica na Pontifícia Universidade de Goiás (2006)

Doutor em Teologia, na área de Teologia Moral (2012), na Faculdade Jesuíta de Filosofia e Teologia de Belo Horizonte - MG Professor de Teologia e Filosofia na Faculdade de Filosofia e Teologia de Goiás (IFITEG) E-mail: elismar01@yahoo.com.br

Recebido em 05/02/2013

Aprovado em 19/06/2013 